\title{
Investigation of Physical Activity Level of Medical School Students
}

\section{Tıp Fakültesi Öğrencilerinde Fiziksel Aktivite Düzeyinin}

\section{Araștırılması}

\author{
Kağan Üçok ${ }^{1}$, Abdurrahman Genç ${ }^{1}$, Ümit Şener ${ }^{1}$, Muzaffer Akkaya $^{1}$, Hakan Mollaoğlư
}

\begin{abstract}
${ }^{1}$ Afyon Kocatepe Tıp Fakültesi Fizyoloji AD, Afyon, Türkiye
\end{abstract}

Eur J Basic Med Sci 2011;1 (1):33-38

Geliș Tarihi (Received): 25.08-2010

Kabul Tarihi (Accepted): 20-09-2010

Correspondence (Yazıșma Adresi):

Doç.Dr. Kağan Üçok, Kocatepe Üniversitesi Tıp Fakültesi, Fizyoloji AD, Temel Tip Bilimleri Binası. Ali Çetinkaya Kampüsü. Izmir yolu 8. km, 03040, Afyonkarahisar, Türkiye

E-posta: kaganucok@hotmail.com

\begin{abstract}
The aim of this study were to investigate the physical activity levels in Afyon Kocatepe University Medical Faculty students and to determine the relationships between the physical activity and the parameters of grade, age, gender, and body mass index (BMI). A questionnaire, short form of the International Physical Activity Questionnaire, was applied to a total of 256 (118 female, 138 male) volunteer students for vigorous and moderate physical activity, walking and sitting times, grade, age, gender, height and weight of the participants. Questionnaire findings were grouped on the basis of student grades. BMI was calculated with formula using height and weight. Total physical activity times of participants were calculated and then classified as low, moderate and high. BMI was in normal limits and total physical activity time (MET-min/week) was in moderate level in students for each grade (1st graders: $1706.8 \pm 1640.4$; 2nd graders: 1873.5 \pm 1495.6 ; 3rd graders: 2049.7 \pm 1963.8 ; 4th graders: $2899.7 \pm 1877.5$; 5 th graders: $2441.7 \pm 1513.7$; 6th graders: $1833.6 \pm 1055.7$ ). However, the value for total physical activity time of the 4th graders was higher than that value for the 1 st graders and the 2 nd graders. The value for daily sitting time ( $\mathrm{min}$ ) of 1 st graders $(572.3 \pm 274.0$ ) was higher than that of the 3 rd

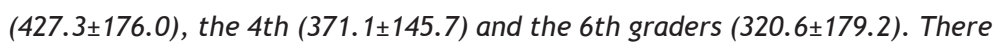
was no correlation among the values in all students excepting the moderate correlation between age and BMI. It was determined that out of 256 students, a total of 47 students had a low level physical activity, whereas a total of 105 students claimed that they did not perform any moderate to vigorous physical activity. It suggests that the 4th graders performed the best physical fitness level among all graders due to having most total physical activity and less sitting time. No association was found between BMI and physical activity times probably because of other factors. Students with low physical activity can be determined and efforts and policies for interventions should be done accordingly.
\end{abstract}

Key Words: Physical activity, young adult, body mass index, student, questionnaire 


\section{ÖZET}

Bu çalıșmanın amacı Afyon Kocatepe Üniversitesi Tıp Fakültesi öğrencilerinde fiziksel aktivite düzeyini sorgulamak ve fiziksel aktivite ile sınıf, yaș, cinsiyet, vücut kütle indeksi (VKi) ilișkilerini belirlemektir. Toplam 256 (118 kı, 138 erkek) gönüllü öğrenciye kısa form Uluslararası Fiziksel Aktivite Anketi uygulandı. Katılımcıların șiddetli ve orta fiziksel aktivite, yürüme ve oturma süreleri, sınıf, yaș, cinsiyet, boy ve kilosu sorgulandı. Anket sonuçları sınıf bazında gruplandırıldı. VKI, boy ve kilodan formülle hesaplandı. Katılımcıların toplam fiziksel aktivite süreleri hesaplanıp düşük, orta ve yüksek düzey biçiminde sınıflandırıldı. Sınıfların ortalama VKi'leri normal ve toplam fiziksel aktivite süreleri (MET-dk/hf) yaklaşık

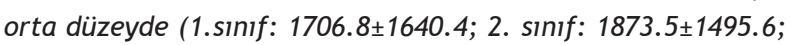
3. sınıf: $2049.7 \pm 1963.8 ; 4$. sınıf: $2899.7 \pm 1877.5 ;$ 5. sınıf: $2441.7 \pm 1513.7$; 6. sınıf: $1833.6 \pm 1055.7$ ) olmasına rağmen 4. sınıfın toplam fiziksel aktivite süresi, 1. sınıf ve 2. sınıf değerlerinden yüksek bulundu $(p<0.05)$. Birinci sınıfın günlük oturma süresi ( $d k)(572.3 \pm 274.0)$, 3. sinıf $(427.3 \pm 176.0) 4$. sınıf $(371.1 \pm 145.7)$ ve 6. sinıf $(320.6 \pm 179.2)$ değerlerinden yüksek bulundu $(p<0.05)$. Tüm öğrencilerde yaș ile VKI arasında $(r=0.338 ; p=0.000)$ bulunan orta düzey korelasyon dışında anlamlı korelasyona rastlanmadı. Toplam 256 öğrenciden, toplam 47 öğrencinin düșük düzeyde fiziksel aktivitesi olduğu, 105 öğrencinin de orta ve șiddetli fiziksel aktivite yapmadığı saptandı. Tıp Fakültesi öğrencileri arasında 4. sınıf, en fazla toplam fiziksel aktivite ve daha az oturma süresi ile en iyi fiziksel zindeliği yakalayan sınıf olarak kabul edilebilir. Sınıfların VKi ile fiziksel aktivite süreleri arasında ilişki bulunmaması VKi'yi etkileyen diğer faktörlerden kaynaklanmış olabilir. Fiziksel aktivitesi düşük olan öğrenciler anket uygulamasıla belirlenip bu kişilerin aktivite düzeyini arttırmaya yönelik girişim ve politikalar yapılmalıdır.

Anahtar Kelimeler: Fiziksel aktivite, genç erișkin, vücut kütle indeksi, öğrenci, anket

\section{GíRiş}

Günümüzde, hareketsiz yaşam tarzı ve kilo alma sık görülen sorunlardır. İnsanların günlük yașantısına giren ev cihazları, asansör ve yürüyen merdivenler, seyahat araçları, iș yerlerinde, fabrika ve tarımda kullanılan makineler gibi birçok teknoloji ürünü fiziksel aktivite ve enerji tüketimini azaltmıștır. Boș zamanların artmasına karșın, insanların çoğu boș vakitlerinde fiziksel aktivite yeterli zaman ayırmamaktadır (1). Fiziksel aktivite, fizyolojik, metabolik, psikolojik parametreleri iyileștirir, birçok kronik hastalık ve erken mortalite riskini azaltır, kemik, kas ve eklem sağlığını sürdürmeye yardımcı olur (2). Düzenli egzersiz kardiyak olayları (enfarktüs, hipertansiyon), tip 2 diyabeti, kolon ve meme kanserini, obeziteyi, depresyon ve anksiyeteyi, safra kesesi hastalıklarını ve osteoporotik kırıkları azaltır $(1,2)$. Aynı zamanda düzenli fiziksel aktivitenin sağlık üzerine yararlı etkileri egzersiz süre ve șiddeti ile ilișkilidir (1). Hareketsiz yașam tarzı, günümüzde daha sık görülmeye başlaması ve sağlık üzerine olumsuz etkileri nedeniyle mücadele edilmesi gereken önemli bir halk sağlığı problemi olarak karșımıza çıkmaktadır. Endüstrileșmiș toplumlarda metabolik riskle ilgili davranıșsal faktörler beslenme değișikliğinin kötü etkileri gibi benzer etkiler sergiler (3). Toplumda obezite oranı gün geçtikçe artmakta ve obez kișiler birçok hastalık için riskli duruma gelmektedir. Obezite tedavisinde diyet, yașam tarzı değișikliği ve egzersiz temel komponentlerdir (4). Obeziteyi önlemede çocukluk ve gençlik döneminde dengeli beslenme, oturma süresini kısıtlama ve hareketli yașam alıșkanlıklarını kazanıma son derece önemlidir. Vücut kütle indeksi (VKi) obezite sınıflamasında yaygın olarak kullanılmaktadır ve obeziteyle açığa çıkabilecek hastalıklarla yakından ilișkilidir $(1,2,5)$.

Bu çalıșmanın amacı, Afyon Kocatepe Üniversitesi Tıp Fakültesi öğrencilerinde fiziksel aktivite șiddet ve süresini sorgulamak ve fiziksel aktivite profilini çıkartmaktır. Ayrıca fiziksel aktivite düzeyinin sınıf, yaș, cinsiyet, vücut kütle indeksi ile ilișkilerini belirlemektir.

\section{GEREÇ VE YÖNTEM}

Gönüllülük esasına göre, Afyon Kocatepe Üniversitesi Tıp Fakültesinde okuyan 256 öğrenciye (118 kadın, 138 erkek) Türkçeye uyarlanmış kısa form "Uluslararası Fiziksel Aktivite Anketi" (UFAA) yüz yüze görüşmeyle uygulandı. Farklı topluluklarda yapılan çalıșmalarda, UFAA'nın güvenilir ve geçerli olduğu gösterilmiștir (6-12). UFAA'nın Türkiye'de geçerlilik ve güvenilirlik çalıșması yapılmıștır (13). Katılımcıların sınıf, yaş, cinsiyet, boy ve kilosu sorgulandı. Anket sonuçları sınıf bazında gruplandırıldı. Vücut kütle indeksi (VKi) boy ve kilodan formülle hesaplandı (Vücut ağırlığı (kg)/ boy $^{2}\left(\mathrm{~m}^{2}\right)$. Anket ile son 7 gün içerisinde șiddetli fiziksel aktivite (futbol, basketbol, aerobik, hızlı bisiklet çevirme, ağırlık kaldırma, yük tașıma vb.) süresi, orta dereceli fiziksel aktivite (hafif yük tașıma, normal hızda bisiklet çevirme, halk oyunları, dans, bowling, masa tenisi vb.) süresi, yürüme ve bir günlük oturma süreleri (dk) sorgulandı. Fiziksel aktiviteyi engelleyecek 
Tablo 1. Tıp fakültesi öğrencilerinin sınıflara göre boy ve kilo dağılımı.

\begin{tabular}{lccc}
\hline Sınıf & $N: 236$ & Boy $(\mathrm{cm})$ & Vücut Ă̆ırlı̆̆ı $(\mathrm{kg})$ \\
\hline 1 & 75 & $171.5 \pm 9.6$ & $63.6 \pm 12.1$ \\
2 & 62 & $170.0 \pm 9.5$ & $64.9 \pm 13.8$ \\
3 & 37 & $169.8 \pm 8.8$ & $62.9 \pm 10.5$ \\
4 & 35 & $172.9 \pm 8.1$ & $69.9 \pm 12.8$ \\
5 & 31 & $176.4 \pm 9.4$ & $76.1 \pm 20.9$ \\
6 & 16 & $174.5 \pm 8.1$ & $74.8 \pm 11.3$ \\
\hline
\end{tabular}

bir rahatsızlığı olanlar çalıșma dıșında tutuldu. Şiddetli, orta aktivite ve yürüme süreleri bazal metabolik hıza karșılık gelen MET'e çevrilerek toplam fiziksel aktivite süresi (MET-dk/hafta) hesaplandı (9). Katılımcıların toplam fiziksel aktivite süreleri sonucuna göre "düșük, orta ve yüksek düzey” biçiminde sınıflandırıldı. Fiziksel Aktivite Düzeyleri (9):

1. Düșük düzey: 600 MET-dk/hafta nın altı.

2. Orta düzey: 600-3000 MET-dk/hafta arası.

3. Yüksek düzey: 3000 MET-dk/hafta üstü.

Veriler SPSS 16.0 istatistik programıyla değerlendirildi. Verilerin normal dağılıma uygunluğu Kolmogorov Smirnov testiyle yapıldı. One-Way ANOVA, t testi ve Pearson korelasyon analizi kullanıldı. Sonuçlar (ortalama \pm standart sapma) olarak verildi. $\mathrm{p}<0.05$ istatistiksel olarak anlamlı kabul edildi.

\section{BULGULAR}

Tıp Fakültesi öğrencilerinin sınıf bazında ortalama boy ve kilo değerleri Tablo 1'de gösterildi. Tablo 2'de sınıfların ortalama yaș ve VKI değerleri verildi. Sınıflara ait haftalık şiddetli, orta ve hafif (yürüme) fiziksel aktivite ortalama süreleri (dk) Tablo 3'de yer almaktadır.

Tablo 2. Tıp fakültesi öğrencilerine ait yaș ve VKI değerleri.

\begin{tabular}{lll}
\hline Sinıf & Yaș $(\mathrm{y} ı \mathrm{l})$ & VKI $\left(\mathrm{kg} / \mathrm{m}^{2}\right)$ \\
\hline 1 & $18.6 \pm 0.8$ & $21.5 \pm 2.8$ \\
2 & $19.8 \pm 0.7$ & $22.2 \pm 3.0$ \\
3 & $20.4 \pm 0.7$ & $21.8 \pm 2.9$ \\
4 & $21.5 \pm 1.4$ & $23.3 \pm 3.3$ \\
5 & $22.7 \pm 0.9$ & $24.2 \pm 4.8$ \\
6 & $24.3 \pm 1.0$ & $24.5 \pm 2.8$ \\
\hline Yaș: Sinıfların hepsi birbirinden farklı bulundu $(p=0.000)$. \\
VKi: 1-5 ( $p=0.001), 1-6(p=0.010), 2-5(p=0.045), 3-5(p=0.022), 3-6(p=0.049)$ \\
sinifları arasinda fark bulundu.
\end{tabular}

Tablo 4'de sınıfların toplam fiziksel aktiviteleri (MET-dk/ hf), fiziksel aktivite düzeyleri (1.,2. ve 3. düzey) ve oturma süreleri (dk/gün) verildi. Sınıfların fiziksel aktivitesi yaklaşık orta düzeyde idi. Bununla beraber toplam 256 öğrenci incelendiğinde, 47 öğrencinin düșük düzeyde fiziksel aktivitesi olduğu saptandı. Toplam öğrencilerin 105 'inin de orta ve șiddetli fiziksel aktivite yapmadığı belirlendi. Tüm öğrencilerde yaş ile VKI arasında ( $r=0.338$; $\mathrm{p}=0.000$ ) bulunan orta düzey korelasyon dıșında anlamlı

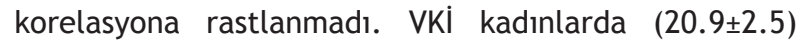
erkeklerden $(23.8 \pm 3.4)$ daha düșük bulundu $(p=0.000)$. Kadın (1951.5 \pm 1712.4$)$ ve erkeklerin $(2146.7 \pm 1656.1)$ toplam fiziksel aktiviteleri (MET-dk/hf) arasında anlaml fark bulunmadı ( $\mathrm{p} 00.05)$. Şiddetli fiziksel aktivite süresi (dk/hf) erkeklerde $(59.2 \pm 91.4)$ kadınlardan $(30.7 \pm 100.3)$ daha yüksek bulundu $(p=0.019)$.

\section{TARTIŞMA}

Fiziksel aktiviteyi anketle belirleme yaygın olarak kullanılmaktadır. Ülkemizin de içinde yer aldığı geniș katılımlı bir çalıșmada kısa form UFAA kullanılarak fiziksel aktivite belirlenmiștir (14). Avrupa Birliği üyesi 27 ülke, Türkiye ve Hırvatistan'da toplam 29193 kișide yapılan bu araștırmada boș vakit fiziksel aktivitesinin sağlık göstergesi olduğu ve izleme amaçlı kullanımının desteklenebileceği rapor edilmiștir (14). Koçak ve ark. (15) Ankara ilinde 54 yașlıda yaptıkları çalıșmada kısa form UFAA ile belirledikleri fiziksel aktivite düzeyinin yașam kalitesi alanlarından fiziksel fonksiyon, enerji/ bitkinlik ve genel sağlık skorları ile ilișkili olduğunu bildirdiler. Bizim çalıșmamız genç erișkin kabul ettiğimiz 256 Tıp Fakültesi öğrencisinde yapıldı ve bu grup açısından düşük fiziksel aktivitesi olanları belirleme gibi önemli sonuçlar elde edildi. Kısa form UFAA'nın geçerli bir yöntem olduğu akselerometre gibi doğrudan günlük fiziksel aktiviteyi ölçen cihazlarla ya da fiziksel aktiviteden etkilenen bir parametre olan egzersiz kapasitesiyle 
Tablo 3. Tıp fakültesi ögrrencilerine ait haftalık șiddetli, orta ve fziksel aktivite ve yürüme süreleri .

\begin{tabular}{lccc} 
Sınıf & Şiddetli Fiziksel Aktivite Süreleri $(d k / h f)$ & Orta Dereceli Fiziksel Aktivite Süreleri (dk/hf) Yürüme Süreleri (dk/hf) \\
\hline 1 & $41.7 \pm 93.7$ & $62.6 \pm 168.3$ & $340.3 \pm 313.3$ \\
2 & $23.6 \pm 53.9$ & $88.1 \pm 160.4$ & $403.8 \pm 363.1$ \\
3 & $83.2 \pm 161.9$ & $91.1 \pm 184.2$ & $308.9 \pm 242.4$ \\
4 & $36.1 \pm 62.8$ & $130.2 \pm 165.0$ & $633.1 \pm 500.9$ \\
5 & $66.5 \pm 98.5$ & $98.2 \pm 139.1$ & $459.7 \pm 296.1$ \\
6 & $49.7 \pm 72.0$ & $24.4 \pm 38.3$ & $405.6 \pm 296.4$ \\
\hline
\end{tabular}

Şiddetli Fiz.Akt. Süresi: $2-3$ ( $p=0.034)$ sınıfları arasında fark bulundu.

Yürüme Süresi : $1-4(p=0.038), 2-3 \quad(p=0.023), 3-4(p=0.017)$ sınıfları arasında fark bulundu.

karșılaștırılarak yapılmıștır $(12,16)$. Ekelund ve ark.(12) İsveçli 185 erișkinde yaptıkları geçerlilik çalışmasında kısa form UFAA'da toplam fiziksel aktiviteyi (MET-dk/ gün) akselerometreyle belirlenen ortalama aktivite șiddeti (aktivite sayısı/dk) ile önemli derecede korale buldular $(r=0.34, P<0.001)$. Papathanasiou ve ark.(16) genç erișkinlerde yaptıkları geçerlilik çalıșmasında toplam 213 katılımcının maksimal Bruce treadmil testiyle aerobik egzersiz kapasitesini ölçtüler ve kısa form UFAA ile fiziksel aktiviteleri sorguladılar. Toplam fiziksel aktivite $(r=0.37)$ ve șiddetli fiziksel aktiviteyi $(r=0.47)$ aerobik egzersiz kapasitesi ile önemli derecede korale buldular (16). Yaptığımız çalıșmada Tıp Fakültesi öğrencilerinde bu geçerli UFAA ile belirlenen fiziksel aktivite düzeyinin, çeșitli amaçlar için kullanılabileceğini düşünmekteyiz. UFAA ile fiziksel inaktiviteyi belirleme konusunda farklı görüșler ileri sürülmüștür $(17,18)$. Hallal ve ark.(17) kısa form UFAA'da haftada 150 dk'dan az orta ya da șiddetli fiziksel aktiviteyi fiziksel inaktivite olarak tanımladılar. Rosenberg ve ark.(18) ise sedanter davranışı belirlemede sadece kısa ve uzun form UFAA ile saptanan oturma süresinin güvenilir olduğunu rapor ettiler. Bizim çalıșmamızda da fiziksel inaktivite, oturma süresi ile değerlendirildi.

Santos ve ark.(19) Portekizli 7330 erișkinde yaptıkları çalıșmada alt yapı tesislerinin dağılımı, hedeflere erișim, sosyal çevre ve estetik görünüșü yüksek fiziksel aktivite düzeyinin belirleyicileri olarak buldular ve fiziksel aktivite düzeyini yükseltmeyi hedefleyen programlarda bu çevresel faktörlerin göz önünde bulundurulması gerektiğini bildirdiler. Tıp Fakültesi öğrencilerinde yaptığımız bu çalıșmada tüm sınıfların VKi ve toplam fiziksel aktivite süreleri normal sınırlardadır. Ancak 4. sınıf, toplam fiziksel aktivite süresinin çokluğu ve oturma süresinin azlığı ile fiziksel zindelik açısından en iyi sınıf kabul edilebilir (Tablo 4). Dördüncü sınıfın toplam fiziksel aktivitesindeki çokluğun büyük oranda yürümeden kaynaklanması (Tablo 3) yürüyüșün en kolay yapılabilen fiziksel aktivite olduğunu akla getirmektedir. Ayrıca toplam fiziksel aktivite süreleri arasında anlamlı fark olmamasına rağmen, șiddetli fiziksel aktivite süresinin erkeklerde kadınlardan daha yüksek bulunması erkeklerin futbol, basketbol gibi șiddetli fiziksel aktiviteyi içeren takım sporlarını daha fazla yapmalarından kaynaklanabilir. Söz edilen bu durumlar yukarıda Santos ve ark. (19)'nın bildirdiği gibi çevresel faktörlerin fiziksel aktiviteyi etkilediğini göstermektedir.

Janssen ve ark.(20) 34 ülkede yaptıkları kesitsel çalıșmada, ülkelerin çoğunda aşırı kilolu çocuklarda normal kilolulara göre fiziksel aktivitenin daha düşük, televizyon seyretme süresinin daha uzun olduğunu buldular. Hallal ve ark.(17) Brezilyalı 3182 erișkinde yaptıkları kesitsel çalıșmada fiziksel inaktivite sıklığını \% 41.1 saptadılar ve çok değișkenli analizlerde fiziksel inaktiviteyi yaș ve sosyoekonomik durumla ilișkili, kișinin kendi bildirdiği sağlık durumu ile zıt ilişsili buldular. Baretta ve ark.(21) Brezilya'nın Santa Catarina, Joaçaba bölgesinde 597 erișkine kısa form UFAA uyguladılar ve fiziksel inaktivite düzeyini Brezilya'nın diğer topluluklarından daha düşük buldular ve bu sonucun düzenli fiziksel aktiviteyi arttırmak için uygun halk sağlığı politikalarına yardımcı olabileceğini bildirdiler. Bizim çalıșmamız Üniversite öğrencisi gençlerde yapıldı. Ancak bundan bașka yukarıdaki çalıșmalarda olduğu gibi ülkemizde de çocuklar, yaşlılar, farklı iş kollarındaki işçiler, memur, kırsal alanlarda ve çeșitli coğrafi bölgelerde yașayanlar ve ev hanımı gibi farklı toplulukların fiziksel aktivite düzeyleri belirlenebilir. Elde edilen veriler toplum sağlığı program ve politikalarında kullanılabilir, özellikle düşük fiziksel aktivitesi olanların aktivitelerini yükseltmeye yönelik spesifik halk sağlığı politikaları geliștirilebilir. 
Tablo 4. Tıp fakültesi öğrencilerinin toplam fiziksel aktiviteleri, fiziksel aktivite düzeyleri $(1,2,3)$ ve oturma süreleri

\begin{tabular}{llcc}
\hline Sinıf & Toplam Fiziksel Aktivite $(M E T-d k / h f)$ & Düzey (1-2-3) & Oturma Süreleri (dk/gün) \\
\hline 1 & $1706.8 \pm 1640.4$ & $1.9 \pm 0.7$ & $572.3 \pm 274.0$ \\
2 & $1873.5 \pm 1495.6$ & $2.0 \pm 0.6$ & $465.3 \pm 189.8$ \\
3 & $2049.7 \pm 1963.8$ & $2.0 \pm 0.7$ & $427.3 \pm 176.0$ \\
4 & $2899.7 \pm 1877.5$ & $2.4 \pm 0.6$ & $371.1 \pm 145.7$ \\
5 & $2441.7 \pm 1513.7$ & $2.3 \pm 0.7$ & $527.2 \pm 302.7$ \\
6 & $1833.6 \pm 1055.7$ & $2.0 \pm 0.4$ & $320.6 \pm 179.2$ \\
\hline
\end{tabular}

Toplam Fiz.Akt.: 1-4 ( $p=0.006), 2-4$ ( $p=0.041)$ sinıfları arasinda fark bulundu.

Oturma süresi: 1 -3 $(p=0.015), 1-4(p=0.000), 1-6(p=0.001)$ sınıfları arasında fark bulundu.

Obezitenin primer sebepleri arasında hipotalamik, endokrin ve genetik hastalıklar, beslenme ve fiziksel inaktivite yer alır (22). Santos ve ark.(23) Portekizli 9991 erișkinde yaptıkları çalıșmada düșük fiziksel aktivitesi ve yüksek oturma süresi (3 saat/gün ya da üzeri) olan erkeklerin büyük olasılıkla obez olduğunu bildirdiler. Zanovec ve ark.(24) vücut yağ yüzdesini tahmin için geliștirdikleri formüllerde VKI, cinsiyet ve ırkın yanı sıra haftalık toplam fiziksel aktivite (MET-saat) süresini kullandıkları zaman daha doğru ve kesin sonuçlar elde ettiler. Wells ve ark.(3) azalmıș uyku süresi ve artmıș televizyon seyretmenin VKi, obezite ve yüksek kan basıncı ile ilișkili olduğunu buldular. Koçak ve ark. (14) yașlılarda UFAA puanlarında, VKI'ye göre istatistiksel olarak anlamlı derecede farklılık gözlemlediler. Bizim çalıșmamızda ise yukarıdaki araștırmaların aksine sınıfların VKi ile fiziksel aktivite süreleri arasında ilișki bulunmadı. Bu durumun VKI'ini etkileyen diğer faktörlerden kaynaklanmıș olabileceğini düșünmekteyiz. Örneğin katılımcılar henüz genç yașta olduklarından, fiziksel aktiviteleri düșük bile olsa beslenme alıșkanlığı ve bazal metabolik hız gibi VKI’yi etkileyebilecek diğer faktörler orta ve ileri yaștakiler kadar etki etmiş olabilir. Öğrencilerin sınıfı yükseldikçe, yașla beraber Vki'nin arttığı (normal sınırlar içinde ola bile) görüldü (Tablo 2). Ayrıca yaș ve VKi arasında orta dereceli pozitif korelasyon saptandı. Bu sonuçlar yaș ilerledikçe kilo almayla uyumlu gözükmektedir (25).

Vücut ağırlığının kontrolü ve bilinçli egzersiz programı kișinin fizik kondisyonunu iyi hale getirerek mortalite riskini azaltır ve uzun bir yașam sürmede önemli bir koșulun yerine gelmesini sağlar (26). Fizik kondisyonun iyi olmasını sağlayacak davranıș alıșkanlıkları çocukluk ve gençlik döneminde kazanılmaktadır. Genç erișkinlerde yaptığımız bu çalıșmada sınıfların fiziksel aktivitesi yaklaşık orta düzeyde olmasına rağmen
47 öğrencinin düșük düzeyde fiziksel aktivitesi olması azımsanmayacak ölçüdedir. Bu öğrencilerin fiziksel aktivite düzeyini arttırmaya yönelik önlemlerin (eğitim, tesis, maddi destek, vb.) alınması gençlerin ileride karșılașabilecekleri sağlık sorunlarını azaltmada son derece önemli rol oynayacağı kanısındayız. Yine toplam 256 öğrenciden 105'inin orta ve șiddetli fiziksel aktivite yapmama nedenleri araștırılmalıdır. Bu tip egzersizleri (futbol, basketbol, tenis, yüzme vb.) yapmayan öğrenci sayısının fazlalığı maddi olanaklarının kısıtlılığı da tesis yetersizliğinden kaynaklanabilir.

Çalıșma kısıtılıkları șu șekilde sayılabilir. Anket öğrencilere üç farklı kiși tarafından uygulandı, bu durum yöntem açısından kısıtlılık kabul edilebilir. Üst sınıflarda katılımcı sayısının azlığı büyük oranda öğrenci sayısının önceki yıllarda az olmasından kaynaklandı. İlk bașlarda fakültedeki öğrenci sayısı 28-30 civarında iken son yıllarda bu sayı 90'ın üzerine çıktı. Ayrıca 15 kadar öğrencinin anket sonucu doğru bilgileri içirmediği düșüncesiyle (örneğin haftada 7 gün ve günde 12 saat şiddetli fiziksel aktivite yapıldığına dair bilgi içermesi) çalıșma dıșında bırakıldı, bazı öğrencilere fakülte dıșında staj yapmaları nedeniyle ulașılamadı, bazı öğrenciler de ankete katılmayı kabul etmedi.

Sonuç olarak Tıp Fakültesi öğrencilerinin fiziksel aktiviteleri orta ve VKI'leri normal düzeydedir. Bununla beraber Tıp Fakültesi öğrencileri arasında 4. sınıf, en fazla toplam fiziksel aktivite ve daha az oturma süresi ile fiziksel zindelik açısından en iyi sınıf olarak kabul edilebilir. Sınıfların VKi ile fiziksel aktivite süreleri arasında ilișki bulunmaması VKI'yi etkileyen diğer faktörlerden kaynaklanmıș olabilir. Fiziksel aktivitesi düșük bulunan öğrencilerin aktivite düzeyini arttırmaya yönelik girișimler halk sağlığı açısından çok sayıda kazanım getirebilir. Bu konuda yapılacak kapsamlı araștırmalarla, 
özellikle çocukluk ve gençlik gibi yaşamın erken döneminde fiziksel aktivitesi düșük olan kișiler kolay ve ucuz bir yöntem olan anket uygulamasıyla belirlenip sonuçları koruyucu politikaların geliștirilmesinde kullanılabilir.

Teșekkür

AKÜ Tıp Fakültesi öğrencileri Feyza Merve Sekkin, Büșra Gürel ve Yusuf Görgülü'ye teșekkür ederiz.

\section{KAYNAKLAR}

1. Heyward VH. Advanced Fitness Assessment and Exercise Prescription. 5th ed. USA: Human Kinetics; 2006. p.211,200 .

2. American College of Sports Medicine (ACSM), ACSM's Guidelines for Exercise Testing and Prescription. 7th ed. Baltimore: Lippincott Williams \& Wilkins; 2006. p.7-9,58.

3. Wells JC, Hallal PC, Reichert FF, Menezes AM, Araújo $C L$, Victora $C G$. Sleep patterns and television viewing in relation to obesity and blood pressure: evidence from an adolescent Brazilian birth cohort. Int J Obes (Lond). 2008;32:1042-9.

4. Ehrman JK, Gordon PM, Visich PS, Keteyian SJ. Clinical Exercise Physiology. 2nd ed. USA: Human Kinetics Publishers; 2005. p.211-213.

5. American College of Sports Medicine. ACSM's HealthRelated Physical Fitness Assessment Manual. 2nd ed. USA: Lippincott Williams \& Wilkins; 2007. p.46,47.

6. Mader $U$, Martin BW, Schutz $Y$, Marti B. Validity of four short physical activity questionnaires in middle-aged persons. Med Sci Sports Exerc 2006;38:1255-66.

7. Arvidsson D, Slinde F, Hulthen L. Physical activity questionnaire for adolescents validated against doubly labelled water. Eur J Clin Nutr. 2005;59:376-83.

8. Brown WJ, Trost SG, Bauman A, Mummery K, Owen N. Test-retest reliability of four physical activity measures used in population surveys. J Sci Med Sport. 2004;7:20515.

9. Craig CL, Mashall AL, Sjöström M, et al. International physical activity questionnaire: 12-country reliability and validity. Med Sci Sports Exerc. 2003;35:1381-95.

10. Hagstromer M, Oja P, Sjostrom M. The International Physical Activity Questionnaire (IPAQ): a study of concurrent and construct validity. Public Health Nutr. 2006;9:755-62.

11. van der Ploeg HP, Tudor-Locke C, Marshall AL, et al. Reliability and validity of the international physical activity questionnaire for assessing walking. Res $Q$ Exerc Sport. 2010 Mar;81:97-101.

12. Ekelund U, Sepp $H$, Brage S, et al. Criterion-related validity of the last 7-day, short form of the International Physical Activity Questionnaire in Swedish adults. Public Health Nutr. 2006;9:258-65.
13. Öztürk M. Üniversitede eğitim-öğretim gören öğrencilerde Uluslararası Fiziksel Aktivite Anketinin geçerliliği ve güvenirliği ve fiziksel aktivite düzeylerinin belirlenmesi. [Yüksek Lisans Tezi]. Ankara: Hacettepe Üniversitesi Sağlık Bilimleri Enstitüsü; 2005.

14. bu-Omar K, Rütten A. Relation of leisure time, occupational, domestic, and commuting physical activity to health indicators in Europe. Prev Med. 2008;47:319-23.

15. Kocak FU, Ozkan F. Yașlılarda Fiziksel Aktivite Düzeyi ve Yaşam Kalitesi. [Physical Activity Levels and the Quality of Life in the Elderly.] Turkiye Klinikleri J Sports Sci 2010;2:46-54.

16. Papathanasiou G, Georgoudis G, Georgakopoulos D, Katsouras C, Kalfakakou V, Evangelou A. Criterion-related validity of the short International Physical Activity Questionnaire against exercise capacity in young adults. Eur J Cardiovasc Prev Rehabil. 2010;17:380-6.

17. Hallal PC, Victora CG, Wells JC, Lima RC. Physical inactivity: prevalence and associated variables in Brazilian adults. Med Sci Sports Exerc. 2003 Nov;35(11):1894-900.

18. Rosenberg DE, Bull FC, Marshall AL, Sallis JF, Bauman AE. Assessment of sedentary behavior with the International Physical Activity Questionnaire. J Phys Act Health. 2008;5 Suppl 1:S30-44.

19. Santos $R$, Silva P, Santos P, Ribeiro JC, Mota J. Physical activity and perceived environmental attributes in a sample of Portuguese adults: results from the Azorean Physical Activity and Health study. Prev Med. 2008;47:83-8.

20. Janssen I, Katzmarzyk PT, Boyce WF, et al. Comparison of overweight and obesity prevalence in school-aged youth from 34 countries and their relationships with physical activity and dietary patterns. Obes Rev. 2005 May;6:12332.

21. Baretta E, Baretta M, Peres KG. Physical activity and associated factors among adults in Joaçaba, Santa Catarina, Brazil. Cad Saude Publica. 2007;23:1595-602.

22. Durstine JL, Moore GE. ACSM's Exercise Management for Persons with Chronic Diseases and Disabilities. 2nd ed. Illinois: Human Kinetics Publishers; 2003. p.149.

23. Santos $R$, Aires L, Santos $P$, Ribeiro JC, Mota J. Prevalence of overweight and obesity in a Portuguese sample of adults: results from the Azorean Physical Activity and Health Study. Am J Hum Biol. 2008;20:78-85.

24. Zanovec M, Johnson LG, Marx BD, Keenan MJ, Tuuri G. Self-reported physical activity improves prediction of body fatness in young adults. Med Sci Sports Exerc. 2009; $41: 328-35$

25. Akgun N. Egzersiz ve Spor Fizyolojisi 2. Cilt. 5. Baski, Ege Üniversitesi Basimevi, Bornova, 1994. p.160

26. Tibbi Fizyoloji. Guyton AC, Hall JE. (Ceviri Editorleri: Cavusoglu H, Yegen BC), 11. Basim, Nobel Tip Kitabevleri, 2007. p. 1066. 